\title{
Typhoon Yolanda and Post-disaster Resilience: problems and challenges
}

\section{Pauline Eadie (School of Politics and International Relations) - Asia Pacific Viewpoint date accepted 16 September 2018}

\section{Introduction}

Typhoon Yolanda hit the Visayas region of the Philippines on 8 November 2013. With wind speeds reaching $315 \mathrm{~km} / \mathrm{h}$, the storm remains one of the strongest and most destructive typhoons ever to make landfall (Santos, 2013). This article focuses on how the concept of 'resilience' was articulated and experienced post-Typhoon Yolanda (international name Haiyan) with reference to the rebuilding and rehabilitation efforts in Tacloban City. Tacloban is the administrative center of the Eastern Visayas (Region VIII) in the Philippines and one of the most heavily urbanized areas to be devastated by Yolanda. This city was chosen as the focus for this article as it became the 'exemplary center' of the relief and rehabilitation effort. It stands as a 'microcosm' (Geertz, 1980: 13) of the institutional and logistical practices common in urban lower and middle-income post-disaster scenarios. Arguably, these practices perpetuate social inequality, operate against a backdrop of 'status pride' (Geertz, 1980: 13) and re-materialize power in ways that consolidate the status quo and profit seeking norms.

Disaster resilience is often related to the management of change or disturbance with the aim of sustainable material wellbeing, for example DFID refers to resilience as 
'maintaining or transforming living standards in the face of shocks or stresses' (2011: 6). The analysis to follow suggests resilience can be understood in terms of the effective management of a set of practices, rather than a condition. Disasters inform resilience as they are the moment when 'the public and its problems are brought into clear view' (Chandler, 2014: 147) and the 'natural' order of things is tested. This case shows that resilience-building strategies must be crafted with reference to specific local socio-economic contexts if they are to be sustainable, effective and properly understood. The experience in Tacloban matters for understanding post-disaster resilience because it is illustrative of the increasingly frequent and intense climate change related threats to urban coastal areas in South-East Asia.

Resilient was a term frequently used by the media, survivors, government officials and various other stakeholders to describe the response to the disaster and those affected by it. I argue that the term is overused, complex and contested, not least because it is socially situated and culturally determined. Resilience building involves examining "the "reality" of processes and relations rather than $[\ldots]$ a top-down imposition seeking to direct, manage or assert control over things' (Chandler, 2014: 13). This article examines the ways that post-disaster resilience is presented as an admirable quality and positive process whilst at the same time shoring up pre-existing power structures and inequalities. I argue that framings of resilience that focus on strength and endurance mask the limitations of post-disaster recovery and marginalise intangible factors such as trust, equity and community cohesion. The rhetoric of resilience matters for survivors as it (re)constructs recovery in ways that limit meaningful change and shuts down dissent. This article investigates the following questions: Firstly, how was resilience articulated and experienced post-typhoon 
Yolanda? And secondly, why do we need a better understanding of resilience for disaster relief and rehabilitation?

Resilience may be driven from the bottom up in ways that are hard to measure. Survivors may take pride in strength through adversity and state that they are resilient when they are not. Or they may simply equate resilience with survival, even under severely diminished conditions of existence. Government and non-governmental agencies and personalities may designate survivors as resilient in order to justify their recovery strategies, without due consideration of what it actually means to be resilient. This interrogation of resilience is important as it offers a way to help unpack the social and material protection of the status quo from above and explains why resilience from below must include social variables such as trust and equity if it is to be sustainable. Nevertheless bottom-up and top-down resilience-building strategies are seldom linear and often context dependent. In order to make sense of these complexities and contradictions, this article considers how resilience was articulated and understood in governmental and non-governmental policy terms and at the community level.

The first section of this paper explains Tacloban's political and geographical vulnerability in relation to Typhoon Yolanda. The second section outlines some of the main themes, issues and complications identified in top-down and bottom-up analyses of disaster resilience. The third section outlines the primary data gathering strategies for this article with an explanation of the area under investigation. The way in which 'resilience' was understood by various individuals and organisations in relation to Typhoon Yolanda is explained in the fourth section. The fifth section outlines how Typhoon Yolanda survivors themselves articulated resilience during fieldwork 
investigations and draws on survey findings. In this section I focus on community, as a form of social capital, and housing and infrastructure, as forms of urban material capital. The sixth section is a discussion that outlines the problems and challenges in resilience-building post-Typhoon Yolanda. Resilience is not just about satisfying material need, it is also about successful social adaptation. I aim to show that the rhetoric of resilience did not match up to the reality after Typhoon Yolanda. In conclusion, I argue that more critical and nuanced investigations are needed on what it really means to be resilient in the urban context post-disaster.

\section{Tacloban City: Geography and Politics}

Official figures indicate 6,293 individuals reported dead, 1,061 missing and 28,689 injured as a result of Typhoon Yolanda, while 591 municipalities were affected and the total damage was estimated at US\$904,680,000 (National Disaster Risk Reduction and Management Council, 2014). An estimated minimum of 31,478 (Lagmay, 2014) informal settlers were living in areas vulnerable to a storm surge at the time of Typhoon Yolanda. Many of these settlers lived on the coastline, or even over the sea, in makeshift wooden structures. During Typhoon Yolanda the storm surge reached five meters high in Tacloban (Nakamura, 2015: 376). The effect on these settlements was catastrophic. The Philippines experiences around 20 typhoons per year and is used to coping with flooding, however, Typhoon Yolanda was exceptional in terms of the damage wrought. At the time of writing rehabilitation work is still ongoing.

Tacloban is a rapidly growing 'highly urbanised city' ${ }^{1}$. In 2010 its population was 221,174 with numbers swelling to 246,115 in 2015 (Philippines Statistics Authority, 
2016: 6). Overall, the economy of the Eastern Visayas is booming with 12.4 percent growth (Recuerdo, 2017) being recorded in 2016, the highest rate of any region in the Philippines. Due to its strategic position, Tacloban is at the center of that boom. However, in common with many other Asian cities (UNESCAP, 2013), Tacloban's growth has resulted in intense competition for urban space.

Tacloban is the bailiwick of the Romualdez family. The current Mayor is Christina Gonzales Romualdez, wife of former Mayor Alfred Romualdez. Former First Lady Imelda Romualdez Marcos is Alfred's aunt and Tacloban is her hometown. Historically the Marcos connection has meant that Tacloban benefitted from the largesse of the Marcoses allowing the Romualdez family to consolidate their economic and political influence (Roces, 1998: 300). As such, there is a special interest in (re)constructing Tacloban as an exemplary centre of the rehabilitation effort as the fortunes of Tacloban are indelibly intertwined with the political credibility and status pride of the Marcos/Romualdez family.

However, the Romualdez/Marcos connection meant that the relationship between Tacloban and the national government was extremely poor under the administration of former President Benigno 'Noynoy’ Aquino III (2010-2016). The Marcos family is widely assumed to have been behind the 1983 assassination of Aquino's father, Benigno 'Ninoy' Aquino Jr., a former Senator and leading opponent of Marcos. Corazon 'Cory' Aquino, wife of Ninoy, assumed the presidency in 1986 when Marcos was ousted by the peaceful EDSA revolution. Noynoy Aquino, who rode a groundswell of support triggered by his mother's death in August 2009, was elected to the presidency in 2010. When President Aquino left office in 2016 it was found 
that 20.7 billion PHP of a 25.6 billion PHP national housing assistant budget and 18.4 billion PHP of a 18.9 billion PHP National Disaster Risk Reduction and Management Fund for Typhoon Yolanda survivors lay undisbursed by the Aquino government (Ager, 2016).

With reference to the overarching focus of this special issue, Clifford Geertz argued that in pre-colonial Bali 'court ceremonialism was the driving force of court politics' (1980: 13) and served to legitimate social inequality and status pride in relation to the exemplary center. It could be argued that comparable rituals legitimize the notion of the 'exemplary family' in the Philippines. Dynastic governance is consolidated through various means including patronage, monuments, rituals such as fiestas and religious ceremonies, the presence of the family at commemorations, celebrations and the visible sponsorship of civic events. Thus legitimizing dynastic rule as the natural order of things. It is also common for politicians to describe themselves as the mother or father of their constituents, therefore invoking notions of benevolent paternalism.

Legitimate hierarchy and good leadership matter for resilience, and relief efforts that ignore or undermine legitimately established structures of command and control risk further disruption to already shattered communities. However 'legitimacy' is not just mandated for by elections; it is also a cultural construction that is reinforced by the issues highlighted above. Disaster rehabilitation practitioners that fail to appreciate the socio-economic and cultural nuances of particular localities, as they relate to resilience, may waste resources and even undermine the very communities that they are trying to help. The complexities of this issue are discussed below. 


\section{What is disaster resilience?}

The term natural disaster should be treated with caution. The scale and impact of natural environmental disasters is mediated by human activity to the extent that there may be little that is 'natural' about their effects. People living in typhoon affected, low lying, densely populated areas in makeshift housing are extremely exposed, and therefore vulnerable to, the vagaries of the weather. This was the case in Tacloban and is a trend that can be more widely identified across the Philippines and elsewhere. Reports suggest the frequency and intensity of typhoons is increasing (Mei and Xie, 2016). Consequently environmental hazards have an increased likelihood of turning into disasters with the poor being least able to mitigate or adapt in the face of such hazards.

The word resilience is derived from the Latin word resilio meaning to leap or spring back. It is a hybrid concept that has been debated across disciplines (Cote and Nightingale, 2012; Folke, 2006; Holling, 1973) in physical/material and social terms, and in relation to governance (Chandler, 2014); community (Aldrich and Meyer, 2015; Cutter et al., 2008), faith (Wilkinson, 2015) and culture (Bankoff, 2003; Kruger et al. 2015). Resilience has relevance for complex post-disaster interventions and for how people and communities recover or 'bounce back'. It is about physical and social evolution that reduces vulnerability to future disasters. Human resilience is not distinct from ecological resilience and any 'delineation between social and ecological systems is artificial and arbitrary' (Folke, 2006: 262). Therefore the institutions and various stakeholders tasked with devising mechanisms for resilience after 
environmental disasters must consider how social and environmental adaptations impact upon each other.

\section{Resilience From Below}

A number of authors have highlighted social capital as a positive determinant of resilience. Daniel Aldrich examines how social capital operates in relation to disasters by examining bonding (kinship, friendship and loyalty amongst those closely connected), bridging (ties between heterogeneous groups) and linking (across vertical authority gradients), capital (2012: 34). Aldrich examines how these links provide information and resources under conditions of crisis and 'illuminate the ways social capital accesses or alters public policies' (2012: 33). Vachette et al. argue that postdisaster bonding social capital is of primary importance for 'trust, relationship building and cooperation [but] bridging and linking ties also play a key role by promoting the exchange of wider information and resources' (2017: 323), a process they refer to as the 'outreach' of bonding social capital.

Greg Bankoff argues that, over time, exposure to frequent seismic and meteorological hazards coupled with weak central leadership in the Philippines has equated to a culture of 'voluntary action for collective benefit' (2007: 328) and in turn the deepening of civic engagement. In an interview article with Curato and Ong Bankoff argues that Filipinos have become 'primarily resilient with great capacities to organize, resist, learn, change and adapt' (Curato and Ong, 2015a, 216). Bankoff and Aldrich both focus on how collective action comes about and the difference that it can make. Under disaster conditions social capital acts as a kind of informal insurance 
involving trust, norms and networks. This is closely linked to social networks and notions of community and mutual labour, known in the Philippines as bayanihan (Gaillard, 2015: 78).

However, post Typhoon Yolanda the social capital-based notions of resilience outlined above were revealed to be overly optimistic. Pauline Eadie and Yvonne Su offer a more negative reading of social capital arguing that people only "“invest" in social capital/relationships because they have the expectation of some sort of return' (2018: 341). After Typhoon Yolanda that 'return' became uncertain due to perceived inequalities in the allocation of relief goods (Ong et al., 2015). Meanwhile those whose homes were destroyed suffered a series of displacements from one temporary home to another whilst also vying with other similarly placed families for limited resources thus creating a 'culture of mistrust' (Curato, 2018). Thus the trust, norms and networks that could have nurtured bottom-up resilience were disrupted. Nevertheless social capital is one of the few sources of capital available to the poor and normatively thought of as a good thing. The potential for effective civic engagement should remain a central issue for resilience building.

\section{Resilience From Above}

Trust, norms and networks also work for the powerful. Consequently, resilience strategies may 'maintain a system in an undesirable state, making recovery or transformation difficult' (Weichselgartner and Kelman, 2014: 5). This argument is informed by Colin Walch who argues that technical, apolitical approaches to resilience are 'often favoured by governments' (2018: 131) as rights-based 
approaches are too politically loaded. Whilst on the other hand, NGOs may 'consider disasters an opportunity to raise people's awareness and mobilise them for social change' (Bankoff and Hilhorst, 2009: 698). Both sides of this debate highlight how resilience can mean different things to different stakeholders and how important social context is to resilience building. This debate matters because there are dangers in resilience strategies that rely on 'command and control styles that risk preserving the status quo, and which might entrench exclusion, and take attention away from the inequality, oppression and entitlement loss that results in cases of proneness to insecurity and disaster (Manyena, 2006: 438). Resilience strategies that resurrect predisaster inequalities and vulnerabilities, or even create new ones, are not resilient at all. Nevertheless an unequal political culture may be so embedded that the status quo is near impossible to shift.

\section{Resilience: Tensions and Contradictions}

David Alexander notes that historically the use of the term resilience has been 'potentially contradictory, such as restoring equilibrium and getting away from it by moving to a new system state' (2013: 2710). Therefore resilience is about both established and evolving social and ecological systems. This contradiction is evident in the definition of resilience: 'the ability of a system and its component parts to anticipate, absorb and accommodate, or recover from the effects of a hazardous event in a timely and efficient manner, including through ensuring the preservation, restoration, or improvement of its basic structures and functions' (IPCC, 2012: 5). The reference above to both preservation and improvement is indicative of both continuity and change. 
Local voices may also have conflicting ideas of how resilience capacity-building should be built. Some may have a vested interest in maintaining the status quo, some may favour different adaptation strategies than others, and some may champion adaptation strategies that may compromise others with effects that are difficult to disentangle. Strategies that are designed to be equitable and inclusive, but are poorly thought out, may result in the already vulnerable being further exposed to harm or in one vulnerability being replaced for another.

Curato and Ong argue that local cultural norms dictate how communities construct the difference between 'acceptable sacrifice and traumatic suffering' (2015b: 16). Meaning that comparable disasters could generate quite different articulations of resilience from similarly affected communities. It is also useful to consider the argument of Bènè et al. who argue that adaptation, rather than being a purely positive notion, involves 'unacceptable trade-offs' (2014: 601) between resilience and wellbeing. Household coping strategies that involve missing meals, neglecting health care (including mental health) or education, or living in inadequate shelter can hardly be considered resilient. Bènè et. al. also argue that disaster rehabilitation strategies that are premised on resilience-building may simply entrench pre-existing vulnerabilities and inequalities. Meanwhile Rigg et al. discuss post-disaster resilience-building with reference to how various aid agencies can disturb social hierarchies and patterns of accumulation meaning that 'resilience is not a quality that can always be computed from pre-existing patterns of wealth and poverty' (Rigg et al, 2008, 150), in other words, disasters can, depending on the social and physical context, disturb the status quo. Overall, real resilience is likely to involve some element of redistribution and 
social justice and this is likely to suit some more than others. As such, the crafting of resilience is also about power and control.

\section{Data Gathering}

Without 'community participation, disaster relief often inadvertently rebuilds [...] structures of vulnerability' (Bhatt and Reynolds, 2012: 74) consequently, this article is based on the premise that local communities should be consulted on how to best build resilient and sustainable disaster relief strategies. The primary data for this article was gathered in seven coastal barangays ${ }^{2}$ in Tacloban. All the barangays were inundated by the storm surge and were populated by informal settlers. They all have areas now designated as 'no-dwell' by the Philippine government (Gardner, 2016). This policy means that no resident is allowed to live within 40 meters of the shoreline.

The multi-dimensional nature of resilience means that it is difficult to set a benchmark against which one is deemed to be resilient or not. Recovery from disasters is often measured in terms of economic growth, the reduction of poverty, or the volume of goods and services supplied. However, these economic variables do little to reflect socio-cultural aspects of resilience. Consequently we asked a range of survey questions relating to community cohesion and material welfare. We also asked whether survivors self-assessed themselves as resilient. The surveys ran in 2015 and 2016. Survey data was complemented by 16 focus group discussions (FGDs), involving specific respondents such as women, the elderly, young people and people with disabilities and their carers. Survey work and FGDs were carried out and transcribed by local Waray speakers in consultation with English speaking partners 
working on this project. Special attention was paid to keywords such as resilience, the nuances of which could have been lost in translation. For resilience we used mabaskog, which translates to strong or robust. Resilience is not an indigenous term and there was no word that also clearly encapsulated the notion of recovery. We also ran small pilot studies to ensure that the meaning of the questions was clear. Our questions were designed to provide us with information on the technical and social issues that helped or hindered resilience-building.

We also interviewed a range of governmental and non-governmental stakeholders in order to cross check what we were hearing from below with what was being heard from above. We interviewed each barangay captain in 2015, 2016 and 2017 about community management challenges since the Typhoon Yolanda. Four of the barangay captains were male and three were female. Two were newly elected to their posts during the 2013 barangay elections on 28 October, less than two weeks before Typhoon Yolanda, whilst the others were re-elected to their positions. At the level of City Hall, Mayor Alfred Romualdez was interviewed in 2015 and Vice Mayor Jerry Yaokasin was interviewed annually from 2014 - 2017. Mayor Christina Romualdez declined to be interviewed for this project. The longitudinal nature of our study allowed us to capture responses before and after the 2016 national elections when Rodrigo Duterte was elected to the presidency. The shift from Aquino to Duterte was significant for Tacloban as President Duterte is politically aligned with the Marcos family. The year-on-year multilevel strategy allowed us to compare the perspectives of different stakeholders in order to build a comprehensive assessment of how resilience was understood, experienced and actioned. 


\section{Resilience and Typhoon Yolanda}

On 10 November 2013, United States President Barack Obama stated that: 'Michelle and I are deeply saddened by the loss of life and extensive damage done by Super Typhoon Yolanda. But I know the incredible resiliency of the Philippine people, and I am confident that the spirit of bayanihan will see you through this tragedy' (ITV News, 2013). Five weeks later, Philippine President Benigno Aquino III stated that: 'the task immediately before us lies in ensuring that the communities that rise again do so stronger, better, and more resilient than before' (Aquino, 2013) when introducing the Reconstruction Assistance on Yolanda (RAY) plan to partner agencies. Pope Francis is also on record as praising 'the deep faith and resilience' (Mayol and Fernandez, 2016) of Typhoon Yolanda survivors.

Resilience was a recurring theme in news reports on the disaster. A National Geographic article on the work of photographer David Guttenfelder, who published a series of images of the aftermath was entitled 'Photojournalist Captures Resiliency in the Philippines After Typhoon Haiyan' (Than, 2013). This article was published just two weeks after the disaster. CNN reported that 'One Year After Haiyan Resilience Builds the Philippines' (Klemming, 2014). The term resilience was also used by a series of aid agencies such as CARE (2016) Oxfam, the UNDP (2013), Save the Children (Bloomer, 2014) and World Vision (Aspi, 2016). In 2016 the Tacloban City Government launched a 'Clean Green and Resilient' environmental campaign (Gaspay, 2016), mirroring the World Bank’s Clean, Green and Resilient 2012-2022 Environment Strategy (World Bank, 2013). Clearly 'resilience' was a go-to term when it came to describing the Philippine people and Typhoon Yolanda 
reconstruction efforts. At the local level we found that resilience was generally understood as matibay ${ }^{3}$, meaning strong or stable, in the local Waray language. Thus notions of adaptation were absent or secondary.

\section{Are we Resilient?}

In 2015 Mayor Alfred Romualdez of Tacloban stated that; "when you deal with humanitarian response you are laying the ground already for recovery and rehabilitation and there should be a definite focus on the people' (2015). He noted that 'resilience should be in every department of the city government and every pillar of growth and progress. Resilience programs should be tailored to fit as every LGU is different' (2015). Romualdez's comments are pertinent as post-disaster humanitarian response is about meeting basic needs in an emergency situation, but the next step is about rehabilitation, and strategies that are sustainable in order to build resilience over the longer term. However, despite the embedded rhetoric of resilience in the relief and recovery effort, local understandings of resilience varied.

In answer to the questions: 'Have you heard the term resilience? What does it mean?' the most common answers in focus groups were: to be sturdy, durable, strong, to have faith, to not be in poverty, having a regular income, having livelihood, being able to withstand calamities, for businesses to be back up and running and for buildings to be reconstructed (often barangay halls were mentioned), to recover quickly from calamities and for utilities to be restored. In one focus group we were told 'we have heard the term but we don't really know what it means' (Mixed Respondents, 2017). One person noted that resilience was 'being like bamboo; it only breaks instead of 
bending during strong winds'. The responses proffered related broadly to personal determination to overcome difficulties, livelihood and housing and infrastructure. In answer to the survey question: 'Did you consider yourself resilient before Typhoon Yolanda?' 76.9 percent of respondents answered yes. In answer to the question 'Do you consider yourself resilient now?' 62.5 percent answered yes in 2015 and 69.2 percent answered yes in 2016. Therefore, even though people differed over what being resilient actually entailed, the majority still classified themselves as being resilient.

The barangay captains that we interviewed tended to equate resiliency with disaster preparedness. During the first round of interviews in October 2015 many captains made reference to Typhoon Ruby, a category three typhoon that hit Tacloban on 7 December 2014. They equated resiliency with the well-organized evacuation of residents to evacuation centers. The efficient dissemination of typhoon warnings by government authorities, specifically the Municipal Disaster Risk Reduction Management Council (MDRRMC) was often cited. The captains also noted that the people were now better educated when it came to disaster preparedness and that people would now voluntarily evacuate when they knew a typhoon was coming. They reported zero casualties in the barangays as a result of Typhoon Ruby. They mentioned 'fighting' calamities, which relates to the idea of 'strength' that was also raised in focus groups. In later years, the captains tended to equate resiliency with community well-being and an ability to cope in the face of ongoing problems with the rehabilitation effort, especially a lack of livelihood and inadequate housing. 
Emelita Montalban, captain of Barangay 88, one of the worst hit areas in Tacloban, stated that resilience was about community and 'peaceful living'. She noted that 'we were in a group helping one another after Yolanda, we were survivors' (2017). In order to improve her communities' resilience she suggested that more disaster training, livelihood training and peace and order initiatives were needed. For Montalban, effective leadership and community cohesion were important for resilience building. She claimed that, prior to Yolanda, people had to be 'forced' ${ }^{4}$ to leave their houses when typhoons were imminent.

Community cohesion was an issue that was also raised by Jerry Yaokasin, Vice Mayor of Tacloban. He suggested that resilience was about being able to 'live a normal life' (2017). He noted that when he saw people enjoying the 2017 Romualdezsponsored Tacloban Sangyaw Festival of Lights, it was 'like nothing happened three years ago. It is a story of resilience and speedy recovery' (2017). Yaokasin also agreed with Montalban in that resilience is about human cooperation and leadership.

However, the following comment from Yaokasin is telling, as it is indicative of a failure to effectively adapt:

After Yolanda we had an opportunity to be a little Singapore, we could have been a blueprint or a road map. But we see the same things; traffic and unsafe electric wires, it is still chaotic. We should have built medium rise tenements for people with more space but we have all these new single rise houses that are eating up agricultural land in the north (2017). 
This comment was Yaokasin's response when we asked him what, with the benefit of hindsight, should have been done differently during the relief and rehabilitation effort. Tacloban's city planning did adapt in the aftermath of Typhoon Yolanda as many residents have now been relocated to more robust housing on higher ground. However these settlements have a number of problems including a lack of utilities and inadequate livelihood provision (Ong, et. al. 2015). Many of these homes were flooded during Typhoon Urduja in December 2017 due to poor drainage and inadequate construction.

\section{What Matters for Resilience?}

Some of the responses above outline practical understandings of resilience such as effective evacuation and material wellbeing, including housing. Community cohesion, or bayanihan, also features as an aspiration and a practical requirement. This section details the impact of perceived inequity in the distribution of relief goods and services, and difficulties in the resettlement process as key impediments to community resilience.

\section{Community Resilience}

The chart below details answers to the question 'To what extent did your community help itself?' This question was asked in relation to the period immediately after Typhoon Yolanda, two years later (2015) and three years later (2016). It refers to issues such as communal rebuilding, the self-organization of tasks such as clearing up and burying the dead and the sharing of resources. 


\section{Table 1}

\section{To what extent did your community help itself after Typhoon Yolanda?}

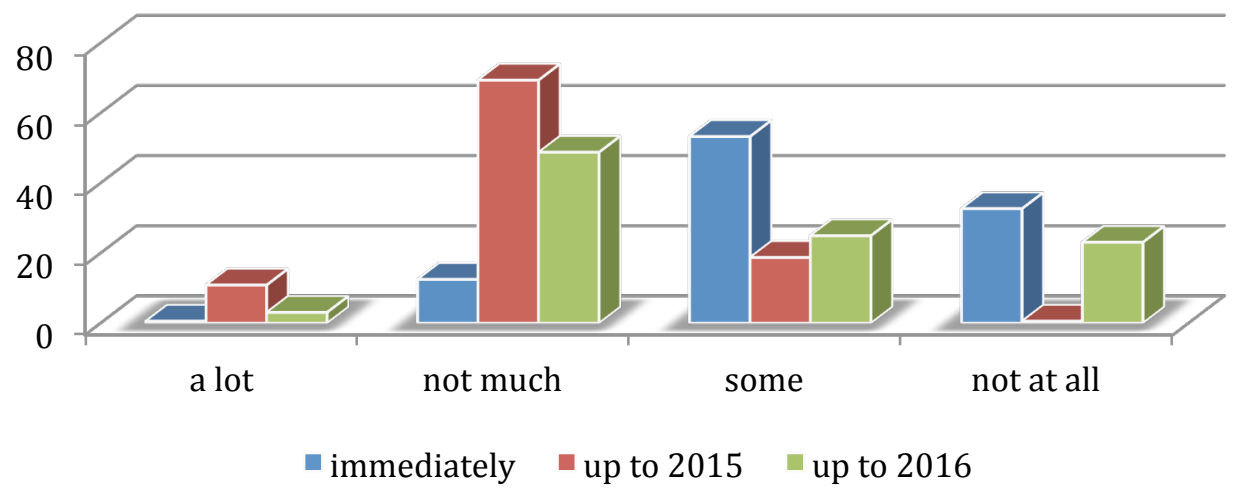

The responses to this question are disappointing given that self-help at the community level is a key factor of the 'bonding' social capital outlined by Aldrich and the notion of bayanihan highlighted by Gaillard and former President Obama. However, the results do correlate with reports from some barangay captains that not all residents who were given 'cash for work' by organizations including Tzu Chi Foundation (Tzu Chi, 2013) did the work required of them, they were 'free riders' that just turned up at the end of the day to collect their 500 PHP allowance. This result correlates with the findings of Yvonne Su and Ladylyn Lim Mangada (2016) who argue that indigenous notions of bayanihan are outmoded and undermined by free riders and arguments over the allocation of relief goods.

Our 2015 survey results indicated that the primary source of support for survivors was 'themselves or their family' with a score of 42.6 percent. However, it was common for extended families to reside within the same barangay, meaning that the distinction between community and family is somewhat blurred. Nevertheless equity was a key issue in relation to community resilience. Focus group discussion evidence 
indicated clearly that many people were unhappy with the way that goods and services were allocated after Typhoon Yolanda and that this had an impact on community relations within the barangay. In some cases a lack of trust was evident with respondents feeling that some barangay captains directed resources towards family members and trusted allies (Field, 2016; Ong, 2016; Wilkinson, 2015) an issue that highlights the negative side of social capital.

\section{Housing and Infrastructure}

According to the Philippine National Risk Reduction and Management Council (2014) Typhoon Yolanda totally damaged 244,550 houses and partially damaged 248,306 in Region VIII alone. Infrastructure damage was estimated at more than $£ 83$ million (2013: 6) ${ }^{5}$. Providing resilient housing in safe areas was one of the stated aims of the National Housing Authority (NHA) in the aftermath of Typhoon Yolanda. The government-decreed 40-meter 'no dwell zone' meant that many families were, in theory, banned from rebuilding their homes in the original location. It was also decreed that families who lost homes in the 40-meter zone would not be eligible for Emergency Shelter Assistance (ESA) funds in order to discourage them from rebuilding in the zone. Instead they would be rehoused further away from the sea.

However many families did rebuild in the no dwell zone, especially in Tacloban. This was because the relocation of those that lived in the zone was an extremely protracted process, involving multiple agencies, that is still ongoing in some areas. With no ESA or affordable alternative building plots available many families had no 
choice but to rebuild makeshift homes in their original locations. In order to rebuild, people were often forced to rely on the largesse of extended family or loans. The rebuilding process often pushed them deeper into poverty. In 2016, 70 percent of our survey respondents reported that the shelter materials they were given were inadequate and only 43 percent reported an offer of moving to a relocation site. In a June 2017 women-only FGD it was reported that house sharers were unable to access duplicate reconstruction materials and were envious of others, possibly resulting in bad feeling in the community. It was common for extended families to stay in one dwelling. In Tacloban the local government effectively abandoned trying to stop rebuilding in the no dwell zone as they were unable to offer any practical alternative.

Resettlement efforts were hampered by a number of problems, including a lack of suitable land (Fitzpatrick and Compton, 2014), a lack of utilities in resettlement zones, and issues over the size and quality ${ }^{6}$ of housing units. After visiting Tacloban on the fourth anniversary of Typhoon Yolanda in November 2017, and seeing first hand the lack of progress, President Duterte ordered a mass movement of people to the government run resettlement sites in Tacloban. This was despite some houses being only partially constructed and ongoing issues with the water supply.

Many transferees still return to their old homes by the sea to work, especially if they are fishermen. Some houses in the no dwell zone have been taken over by families that have moved to Tacloban in the hope of finding work. Other coastal areas, notably Anibong, were not included in the mass movement and residents mostly remain by the sea. Many residents prefer this as they remain in close proximity to their livelihood. In comparison to other cases in this special issue (Tran with 
reference to street vendors in Hanoi, Ramalho with reference to disaster risk reduction in Manila and Cebu, and Tilley et al. in relation to kampung 'urban village' dispossession in Jakarta) the local government in Tacloban has been relatively inattentive in clearing the no dwell zone. This is potentially because a more forceful approach could trigger a backlash, as many people have still not been offered a viable alternative.

\section{Discussion}

It seems that resilience is something to aspire to and it is normatively understood as being a 'good thing' or an admirable characteristic. However, there is little consensus on what resilience is. It is a complex process rather than a quantifiable end point. Typhoon Yolanda survivors surveyed for this project overwhelmingly confirmed that they considered themselves to be resilient. People generally identified 'strength' as being a positive attribute in relation to resilience. However, the ability to absorb shocks through negative coping strategies does little to reduce inequality or promote resilience. Negative strategies do not improve or adapt the lives of individuals and communities. Reducing food intake, living in substandard housing with inadequate sanitation, increased debt, the increase of excessive working hours in 'own account' (informal) or family work or child labour are not positive adaption strategies. It is particularly worrying that negative coping strategies can be casually equated to positive connotations of resilience by both survivors and aid agencies.

It was evident that the management of some of the rehabilitation strategies used post Typhoon Yolanda had the effect of undermining community cohesion as opposed to 
making it strong. Multiple displacements fractured community life and thick trust was undermined. Equity in the distribution of rehabilitation goods and services was an important issue for survivors. A lack of equity tended to generate suspicion and distrust in communities when it was perceived that some were favoured more than others. There was the perception that those aligned with barangay captains and the mayor were more likely to receive favourable treatment

Aid agencies were heavily reliant on local government personnel to provide information on those qualified to receive aid. Many individuals felt that this system was unfair. It is for this reason that people were surprisingly enthusiastic about the raffle system for the allocation of National Housing Association lots in relocation areas. Despite the fact that the raffle meant that extended families might be split up and bonding social capital threatened by distance, people preferred this to government personnel deciding on the allocation. Beneficiaries were suspicious that housing units would not be allocated fairly if the authorities were in charge of the allocations.

Leadership is also an important issue for resilience. Resilience is about building both stability and the conditions necessary for successful adaptation, therefore it is important that systems of command and control are visionary and efficient. However, the entrenched nature of patronage politics in the Philippines (Hutchcroft and Rocamora, 2003; Lange, 2010) means that leaders (patrons) are unlikely to be effectively challenged. In Tacloban there has been no adaptation in governance at the local level, with poor relations between the local and national government being evident until President Rodrigo Duterte took office in 2016. There have been no 
barangay elections since Typhoon Yolanda, ${ }^{7}$ so barangay leadership remains the same unless the captains were replaced for some other reason. For disaster relief practitioners this situation is indicative that account must be taken of local patterns of political power as this can distort, manipulate or facilitate resilience-building.

One of the core ideas of resilience is that communities should be empowered to help themselves. But our survey results show that the general consensus was that communities did not come together efficiently in order to bring about their own rehabilitation. This consensus is due, at least in part, to the perception that goods and services were not allocated equally in the aftermath of Typhoon Yolanda. When asked 'what would you have done differently?' many respondents said that they would have ensured fairness in the distribution of aid. Equity matters for resilience. It matters for the distribution of aid, socio-economic opportunity and so that survivors have a voice in how their communities can adapt and improve.

However if communities are to be consulted on resilience-building then it is important that this is done in a meaningful fashion. Well-meaning but clumsy top-down interventions that fail to appreciate the institutional and cultural operation of local hierarchies can do more harm that good. Bill Cooke and Uma Kothari identify the following scenarios as being particularly problematic for participatory approaches in general development efforts:

- Participatory facilitators override existing legitimate decision-making processes.

- Group dynamics lead to participatory decisions that reinforce the 
interests of the already powerful.

- Participatory methods drive out alternative strategies that may have advantages participation cannot provide (2001: 7-8).

The points raised above are relevant for participatory disaster relief and rehabilitation. If outside agencies forcibly override existing systems of command and control then this may undermine local hierarchies. Whilst these hierarchies might not be perfect they may be legitimate and undermining them could lead to destabilizing power struggles. Alternatively, 'participatory' approaches may just be hi-jacked by the already powerful leading to resentment in communities or effective leadership may be sacrificed at the altar of participation. The danger of everyone having their say is that nothing gets done. Leadership is important for resilience-building, however, this leadership needs to be legitimate, accountable, self-reflexive and capable of adapting for the greater good.

\section{Conclusion}

The term resilience has been used somewhat carelessly in media and policy circles. Evidence shows Typhoon Yolanda survivors also referred to themselves as resilient, even when the conditions of their existence were miserable. Since Typhoon Yolanda resilience has been equated, locally and nationally, with strength rather than the effective management of the complicated process of recovery. This framing has been top down as well as bottom up and has served to gloss over the complex challenges of resilience-building. 
Tacloban, as the exemplary center of the Typhoon Yolanda relief efforts, was indelibly linked to the political fortunes and status pride of the Romualdez/Marcos family. The recovery of the city was concomitant with that of the family and this link was manifest in rituals, celebrations and commemorations, local government run recovery schemes and endorsements. These rituals lauded the resilience and survival of the people and the city. This narrative served to shore up the political status quo and mask the recreation of material inequalities. The terminology of resilience was potentially used as a 'disclaimer' for the failings of the relief effort. That is: survivors are used to these types of disturbances therefore they will have an innate ability to cope. This effectively reduced resilience to a state of mind. However resilience is more than an attitude or the ability to survive at a basic level of existence. It is about adapting socioeconomic institutions and the natural environment in order to mitigate future disturbances.

Resilience is not achieved through survivors adopting negative coping strategies such as a reduction in food or education. It involves access to material and social resources that bring about an improved ability to absorb, adapt or transform in the face of future disturbances of stressors. However, in societies where the already powerful are well served by existing power configurations transformation, or even certain adaptations, may be resisted. This is not necessarily done overtly but rather by normalizing strategies that support the status quo. In most of the communities that we examined people had adapted, but conditions of life had not necessarily improved. Material adaptations, such as the development of new residential areas, were often poorly planned, crippled by red tape and under-resourced. Nevertheless, survivors tended to designate themselves as resilient. This was potentially because the terminology of 
'resilience' does not exist in the local language and interpretations have tended to focus on personal or collective strength rather than a technical process. For disaster relief practitioners and researchers these nuances are important.

Disaster risk reduction has improved in terms of psychological attitudes and material resources in Typhoon Yolanda affected areas. Early warning systems have been enhanced, typhoon resistant evacuation centers have been physically improved and people are psychologically attuned to the need to evacuate when there are typhoon warnings. Nevertheless, disaster relief agencies need to think more carefully about what it means to be resilient and how this can be measured in social and material terms. Indicators of resilience such as safe housing or confidence in community and trust in 'leaders' intersect and impact upon one another. Therefore the relationship between indicators as well as their volume is important.

Resilience has become a policy narrative for disaster relief agencies at international, national and local levels, however, technical and social understandings of what it means to be resilient are complex and sometimes contradictory. The findings in this article reinforce the scholarship that identifies the tension between restoring the status quo and adaptive resilience strategies with particular reference to the dispossession and relocation that many typhoon survivors face. They also highlight the difficulties of equitable and inclusive strategies, that may be desirable, but are in reality inefficient and hard to police.

Non-tangible variables such as faith, trust and community cohesion add to the complexity of what it means to be truly resilient. Optimist narratives of resilience 
serve to mask sub-standard recovery and the failure to improve the living conditions of many survivors. Policy-makers and relief agencies tasked with disaster recovery should adopt more nuanced approaches to resilience building. They should also reflect on how the narrative of resilience is produced and consumed and to what end. Disaster relief practitioners also need to be realistic about what they can achieve. Disaster rehabilitation efforts are unlikely to 'fix' disaster prone societies characterized by inequality, poverty, corruption and weak or unstable governance even before disasters hit or stressors reach crisis point.

\section{References}

Ager, M. (2016) P20B 'Yolanda' housing fund for 2016 not released by Aquino administration, Philippines Daily Inquirer, 8 November. Retrieved 3 September 2018, from website: http://newsinfo.inquirer.net/842063/p20b-yolanda-housing-fund-for2016-not-released-by-aquino-admin.

Aldrich, D. P. (2012) Building Resilience: Social Capital in Post-Disaster Recovery, Chicago and London: The University of Chicago Press.

Aldrich, D. P. and M. A. Meyer (2015) Social Capital and Community Resilience, American Behavioural Scientist, 59(2): 254-269.

Alexander, D. E. (2013) Resilience and Disaster Risk Reduction: an Etymological journey, Natural Hazards and Earth System Sciences', 13(11): 2707-2716 
Aquino, B. S. III (2013) Speech of President Aquino at the briefing on Yolanda Reconstruction Assistance Plan, December 18, Manila. Retrieved 3 September 2018 from website: http://www.officialgazette.gov.ph/2013/12/18/speech-of-presidentaquino-at-the-briefing-on-reconstruction-assistance-on-yolanda/.

Aspi, A. (2016) Philippines more resilient 3 years after Typhoon Yolanda, World Vision, 7 November. Retrieved 3 September 2018, from website: http://www.wvi.org/asia-pacific/article/philippines-more-resilient-3-years-afteryolanda.

Bankoff, G. (2003) Cultures of Disaster: Society and natural hazard in the Philippines, London and New York: Routledge.

Bankoff, G. (2007) The Dangers of Going It Alone: social capital and the origins of community resilience in the Philippines, Continuity and Change, 22(2): 327-355.

Bankoff, G. and D. Hilhorst (2009) The Politics of Risk in the Philippines: comparing state and NGO perceptions of disaster management, Disasters, 33(4): 686-704.

Bhatt, M. R. and T. Reynolds (2012) Community- Based Disaster Risk Reduction: Realizing the Primacy of Community, in C. Emdad Haque and D. Etkin (eds.), Disaster, Risk and Vulnerability: Mitigation through Mobilizing Communities and Partnerships, pp. 71-90. Montreal and Kingston: McGill-Queen's University Press. 
Bloomer, D. B. (2014) The Children of Typhoon Haiyan: Tales of Resiliency, Heroes and Recovery - Part 3, Save the Children, 10 January. Retrieved 3 September 2018: http://savethechildren.typepad.com/blog/2014/01/the-children-of-typhoon-haiyantales-of-resiliency-heroes-and-recovery-part-3.html. ,

CARE (2016) Typhoons in the Philippines: a journey to disaster resilience, 25 February. Retrieved 19 October 2017, from website: https://www.careinternational.org.uk/stories/typhoons-philippines-journey-disasterresilience.

Chandler, D. (2014) Resilience: The Governance of Complexity, London and New York: Routledge.

Cooke, B. and U. Kothari (2001) The Case for Participation as Tyranny, in B. Cooke, B. and U. Kothari (eds.), Participation: The New Tyranny, pp. 1-15. London and New York: Zed Books.

Cote, M. and A. J. Nightingale (2012) Resilience thinking meets social theory: Situating social change in socio-ecological systems (SES) research, Progress in Human Geography, 36(4): 475-489.

Curato, N. (2018) From authoritarian enclave to deliberative space: governance logics in post-disaster reconstruction, Disasters, online version no issue assigned. 
Curato, N. and J. C. Ong (2015a) Cultures of Disaster Revisited: An interview with Greg Bankoff, Philippine Sociological Review, 63: 207-216.

Curato, N. and J. C. Ong (2015b) Disasters Can Lift Veils: Five Issues for Sociological Disaster Studies, Philippine Sociological Review, 63: 1-26.

Cutter, S. L., L. Barnes, M. Berry, C. Burton, E. Evans, E. Tate and J. Webb (2008) A place-based model for understanding community resilience to natural disasters, Global Environmental Change, 18(4): 598-606.

DFID (2011) Defining Disaster Resilience: A DFID Approach Paper, DFID: London. Retrieved 28 June 2018, from website: https://assets.publishing.service.gov.uk/government/uploads/system/uploads/attachme nt_data/file/186874/defining-disaster-resilience-approach-paper.pdf.

Eadie, P. and Y. Su (2018) Post-disaster social capital: trust, equity, bayanihan and Typhoon Yolanda, Disaster Prevention and Management, 27(3): 334-345.

Field, J. (2016) The Philippines and Typhoon Haiyan: The Humanitarian Context, Humanitarian Effectiveness Project. Retrieved 27 September 2017, from website: http://humanitarianeffectivenessproject.com/wpcontent/uploads/2016/05/Philippines_Jessica_Field_HAT.pdf.

Fitzpatrick, D. and C. Compton (2014) Beyond Safe Land: Why security of land tenure is crucial for the Philippines post-Haiyan recovery, Oxfam Joint Agency 
Briefing Paper, August. Retrieved 3 September 2018, from website: http://policypractice.oxfam.org.uk/publications/beyond-safe-land-why-security-of-land-tenure-iscrucial-for-the-philippines-pos-324557.

Folke, C. (2006) Resilience: The emergence of a perspective for socio-ecological systems analyses, Global Environmental Change, 16(3): 253-267.

Gaillard, J. C. (2015) People's Response to Disasters in the Philippines, Vulnerability, Capacities and Resilience, New York: Palgrave MacMillan.

Gardner, J. (2016) Land tenure issues complicate rebuilding after disaster strikes National Catholic Reporter' 6 January. Retrieved 14 December 2017, from website: https://www.ncronline.org/news/world/land-tenure-issues-complicate-rebuildingafter-disaster-strikes.

Gaspay, G. B. (2016) Tacloban Launches Clean, Green, Resilient Tree Planting and Growing Campaign, 10 August. Retrieved 19 October 2017, from website: http://tacloban.gov.ph/tacloban-launches-clean-green-resilient-tree-planting-growingprogram/\#.Wei8J62ZNBx.

Geertz, C. (1980) Negara: the theatre state in nineteenth-century Bali, Princeton: Princeton University Press.

Holling, C. S. (1973) Resilience and stability of ecological systems, Annual Review of Ecology and Systematics, 4: 1-23. 
Hutchcroft, P. and Rocamora, J. (2003) Strong Demands and Weak Institutions: The Origins and Evolution of the Democratic Deficit in the Philippines, Journal of East Asian Studies', 3(2): 259-292.

IPCC (2012) Managing the Risks of Extreme Events and Disasters to Advance Climate Change Adaptation, Cambridge University Press: Cambridge. Retrieved 3 September 2018, from website: https://www.ipcc.ch/pdf/specialreports/srex/SREX Full_Report.pdf.

ITV News (2013) Obama: Philippine People "Incredibly Resilient", 10 November. Retrieved 3 September 2018, from website: http://www.itv.com/news/update/201311-10/obama-philippine-people-incredibly-resilient/.

Klemming Nordenskiöld, S. (2014) One Year After Haiyan Resilience Builds the Philippines, CNN, 7 November. Retrieved 3 September 2018, from website: http://edition.cnn.com/2014/11/06/world/asia/philippines-typhoon-haiyan-oneyear/index.html.

Kruger, F., G. Bankoff, T. Cannon, B. Orlowski and E. L. F. Schipper (eds.) (2015) Cultures and Disasters: Understanding cultural framings in disaster risk reduction, Abingdon: Routledge.

Lagmay, A. M. (2014) Estimate of Informal Settlers at Risk From Storm Surges vs. Number of Fatalities in Tacloban City (YolandaPH), Nationwide Operational 
Assessment of Hazards Project NOAH). Retrieved 3 September 2018, from website: http://center.noah.up.edu.ph/estimate-of-informal-settlers-at-risk-vs-number-offatalities-in-tacloban-city/.

Lange, A. (2010) Elites and Local development in the Philippines, Development and Change, 41(1): 53-76.

Manyena, S. B. (2006) The Concept of Resilience Revisited, Disasters, 30(4): 434350.

Mayol, V. A. and C. E. Fernandez (2016) Pope Francis again extols Pinoys' deep faith and resilience in the face of tragedy as IES closes, Philippines Daily Inquirer, 31 January. Retrieved 3 September 2018, from website: http://globalnation.inquirer.net/135926/pope-francis-again-extols-pinoys-deep-faith$\underline{\text { resilience-in-face-of-tragedy-as-iec-closes. }}$

Mei, W. and S. Xie (2016) Intensification of Landfalling Typhoons over the Northwest Pacific since the late 1970s, Nature Geoscience, 9(October): 753-757.

Mixed Respondents (2017) Focus Group Discussion, 17 June, Tacloban.

Montalban, E. (2017) Interview, 9 June, Tacloban.

Nakamura, R. et al. (2015) Evaluation of Storm Surge Caused by Typhoon Yolanda (2013) and Using Weather - Storm Surge - Wave Tide Model, Procedia Engineering, 
116(1):373-380.

National Disaster Risk Reduction and Management Council (2014) SitRep No. 108 Effects of Typhoon Yolanda (Haiyan), 3 April. Retrieved 3 October 2018, from website:

http://www.ndrrmc.gov.ph/attachments/article/1329/Effects_of_Typhoon_YOLAND A_(HAIYAN)_SitRep_No_108_03APR2014.pdf.

Ong, J. C. J. M. Flores and P. Combinido (2015) Obligated to be Grateful: How local communities experienced humanitarian actors in the Haiyan response, Plan International, May. Retrieved 3 September 2018, from website: https://lra.le.ac.uk/bitstream/2381/33421/2/Obliged $\% 20$ to $\% 20 B e \% 20 G r a t e f u l \% 20-$ \%20final.pdf.

Ong, J. C. (2016) Hidden Injuries of Humanitarian Relief', CDAC Network, 23 February 2015. Retrieved 27 September 2017: from website: http://www.cdacnetwork.org/i/20150223164553-xdmv2.

Philippines Statistics Authority (2016) 2016 Regional Social and Economic Trends: Eastern Visayas Region, Republic of the Philippines Regional Statistical Services Office VIII: Tacloban City.

Recuerdo, E. (2017) Construction boom to sustain economic gains of Eastern Visayas, Business Mirror, 10 May. Retrieved 3 September 2018: https://businessmirror.com.ph/construction-boom-to-sustain-economic-gains-of- 
eastern-visayas/.

Rigg, J., C. Grundy-Warr, L. Law and M. Tan-Mullins (2008) Grounding a natural disaster: Thailand and the 2004 tsunami, Asia Pacific Viewpoint, 49(2): 137-154.

Roces, M. (1998) The gendering of post-war Philippine politics, in K. Sen and M. Stivens, (eds.), Gender and Power in Affluent Asia, pp. 291-316. London and New York: Routledge,

Romualdez, A. (2015) Interview, 11 November, Tacloban.

Santos, R. Jr. (2013) Yolanda and the World's Strongest Storms, Rappler, 10 July. Retrieved 14 September 2018, from website: https://www.rappler.com/sciencenature/43351-world-strongest-cyclones-history.

Su, Y. and L. L. Mangada (2016) Bayanihan After Typhoon Yolanda: are we romanticizing an indigenous coping strategy?, Humanitarian Practice Network, 10 August. Retrieved 3 September 2018, from website: https://odihpn.org/blog/bayanihan-after-typhoon-haiyan-are-we-romanticising-anindigenous-coping-strategy/.

Than, K. (2013) Photojournalist Captures Resiliency in the Philippines After Typhoon Haiyan, National Geographic, 23 November. Retrieved 3 September 2018, from 
website: http://news.nationalgeographic.com/news/2013/11/131123-davidguttenfelder-photography-typhoon-haiyan-philippines/.

Tzu Chi (2013) Tzu Chi's cash-for-work program continues in Tacloban, 21 November, Taiwan Buddhist Tzu Chi Foundation Philippines. Retrieved 3 September December 2018, from website: http://tzuchi.org.ph/special_report/tzu-chis-cash-forwork-program-continues-in-tacloban-2/.

UNDP (2013) Post-Disaster Recovery and Resilience in Typhoon Yolanda Affected Areas: Immediate Response Initiatives from the UNDP, December. Retrieved 3 September 2018, from website: http://www.alnap.org/pool/files/undp-support-postyolanda-recovery-project-chapeau.pdf.

UNESCAP (2013) Factsheet: Urbanization Trends in Asia and the Pacific, November. Retrieved 3 September 2018, from website: http://www.unescapsdd.org/files/documents/SPPS-Factsheet-urbanization-v5.pdf.

Vachette, A., D. King and A. Cottrell (2017) Bonding, bridging and linking social networks: A qualitative study of the emergency management of Cyclone Pam, Vanuatu, Asia Pacific Viewpoint, 58(3): 315-330.

Walch, C. (2018) Typhoon Haiyan: pushing the limits of resilience? The effect of land inequality on resilience and disaster risk reduction policies in the Philippines, Critical Asian Studies, 50(1): 122-135. 
Weichselgartner, J. and I. Kelman (2014) Geographies of Resilience: Challenges and Opportunities of a Descriptive Concept, Progress in Human Geography, 39(3): 1-19.

Wilkinson, O. (2015) Faith and Resilience After Disaster: The Case of Typhoon Haiyan, November, Misean Cara. Retrieved 6 October 2017, from website: http:/www.miseancara.ie/wp-content/uploads/2016/02/Faith-Resilience-After-

Disaster.pdf.

Yaokasin, J. (2017) Interview, 15 June, Tacloban.

\section{Endnotes}

\footnotetext{
${ }^{1}$ In the Philippines 'highly urbanised' cities have populations of at least 200,000 and an annual income of at least 50 million PHP based on 1991 constant prices. Tacloban was declared 'highly urbanized' in 2008.

${ }^{2}$ A barangay is the smallest administrative area in the Philippines. The barangays are: 54, 54-A, 66-A, $67,87,88$ and 89.

${ }^{3}$ Matibay is very similar to mabaskog (meaning strong or robust), the word we used to reference resilience in our survey questions.
}

${ }^{4}$ Many people did not evacuate during Typhoon Yolanda as people stayed at home to safeguard their livestock and property. This was common practice, with men and older boys staying behind whilst the women and younger children went to evacuation centers.

${ }^{5}$ Based on a conversion rate of $60 \mathrm{PHP} / 1 \mathrm{GBP}$.

${ }^{6}$ Currently the subject of a Congressional Hearing in the Philippines. Contractors have been accused of using sub-standard materials. See (Nonato, 2017).

${ }^{7}$ President Rodrigo Duterte postponed the elections saying that many barangay captains were involved in the drugs trade. 
